\title{
Caffeic acid phenethyl amide ameliorates ischemia/reperfusion injury and cardiac dysfunction in streptozotocin-induced diabetic rats
}

Yi-Jin Ho ${ }^{1}$, An-Sheng Lee ${ }^{2}$, Wen-Pin Chen ${ }^{1}$, Wei-Lung Chang ${ }^{1}$, Ying-Kang Tsai ${ }^{1}$, Hsi-Lin Chiư ${ }^{3}$, Yueh-Hsiung Kuo ${ }^{4,5}$ and Ming-Jai Su ${ }^{*^{*}}$

\begin{abstract}
Background: Caffeic acid phenethyl ester (CAPE) has been shown to protect the heart against ischemia/reperfusion (I/R) injury by various mechanisms including its antioxidant effect. In this study, we evaluated the protective effects of a CAPE analog with more structural stability in plasma, caffeic acid phenethyl amide (CAPA), on I/R injury in streptozotocin (STZ)-induced type 1 diabetic rats.

Methods: Type 1 diabetes mellitus was induced in Sprague-Dawley rats by a single intravenous injection of $60 \mathrm{mg} / \mathrm{kg}$ STZ. To produce the I/R injury, the left anterior descending coronary artery was occluded for 45 minutes, followed by 2 hours of reperfusion. CAPA was pretreated intraperitoneally 30 minutes before reperfusion. An analog devoid of the antioxidant property of CAPA, dimethoxyl CAPA (dmCAPA), and a nitric oxide synthase (NOS)

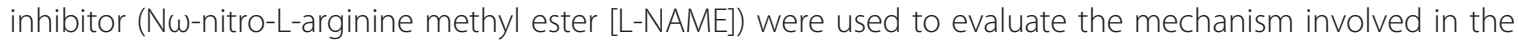
reduction of the infarct size following CAPA-treatment. Finally, the cardioprotective effect of chronic treatment of CAPA was analyzed in diabetic rats.
\end{abstract}

Results: Compared to the control group, CAPA administration (3 and $15 \mathrm{mg} / \mathrm{kg}$ ) significantly reduced the myocardial infarct size after I/R, while dmCAPA (15 mg/kg) had no cardioprotective effect. Interestingly, pretreatment with a NOS inhibitor, (L-NAME, $3 \mathrm{mg} / \mathrm{kg}$ ) eliminated the effect of CAPA on myocardial infarction. Additionally, a 4-week CAPA treatment ( $1 \mathrm{mg} / \mathrm{kg}$, orally, once daily) started 4 weeks after STZ-induction could effectively decrease the infarct size and ameliorate the cardiac dysfunction by pressure-volume loop analysis in STZ-induced diabetic animals.

Conclusions: CAPA, which is structurally similar to CAPE, exerts cardioprotective activity in I/R injury through its antioxidant property and by preserving nitric oxide levels. On the other hand, chronic CAPA treatment could also ameliorate cardiac dysfunction in diabetic animals.

Keywords: Diabetes, Ischemia/reperfusion injury, Caffeic acid phenethyl amide

\footnotetext{
* Correspondence: mingja@ntu.edu.tw

'Department of Pharmacology, College of Medicine, National Taiwan

University, 11F, No. 1, Sec. 1, Jen-Ai Road, Taipei 10051, Taiwan

Full list of author information is available at the end of the article
} 


\section{Background}

Numerous clinical studies have shown that subjects with diabetes face an increased risk of mortality from coronary heart disease, such as myocardial infarction and stroke [1]. Accordingly, the infarct size of the heart is increased in streptozotocin (STZ)-induced type 1 diabetic rats under ischemia/reperfusion (I/R) injury [2,3].

In the pathology of myocardial infarction, injury is more dominant from reperfusion than that from ischemia and reactive oxygen species (ROS) generation is thought to be the main cause of reperfusion injury [4]. Therefore, antioxidant therapy should effectively reduce I/R injury [5].

Caffeic acid phenethyl ester (CAPE) is the major component in propolis extracts with known anti-inflammatory [6], anti-viral [7], cancer cell inhibitory [8], anti-bacterial [9], antioxidant [10], and free radical scavenging activities [9]. CAPE significantly decreased fasting blood glucose, alanine aminotransferase, cholesterol, and triglyceride levels and protected the brain against oxidative stress and inflammation in diabetic rats $[11,12]$. The 12-week oral administration of CAPE $(30 \mathrm{mg} / \mathrm{kg})$ slowed the atherosclerosis progress in apolipoprotein E-deficient mice [13]. In addition, CAPE administration protects many organs such as the brain [14], bone marrow [14,15], kidney [16], lung [17] and ovary [18] against $I / R$ injury. In the heart, CAPE can also protect against $\mathrm{I} / \mathrm{R}$ injury by various mechanisms [19-23] including its antioxidant activity.

A CAPE analog, caffeic acid phenethyl amide (CAPA, $N$-trans-caffeoyl- $\beta$-phenethylamine), synthesized from 3,4methylene-dioxy-cinnamic acid, with an amide linkage between caffeic acid and the phenethyl group that resists hydrolysis within the circulation, was recently found to be more stable than CAPE in rat plasma [24]. CAPA presents a significantly longer elimination half-life in the systemic circulation than CAPE after intravenous administration into male rats [25]. It exerts beneficial effects by its free radical scavenging and antioxidant activity [26,27] and displays a cytoprotective effect against $\mathrm{H}_{2} \mathrm{O}_{2}$-induced cell death in human umbilical vascular endothelial cells [28]. CAPA could also improve glucose homeostasis by $\alpha$ glucosidase inhibition [29], adiponectin induction [30] in vitro, stimulating insulin secretion and reducing plasma glucose in diabetic rats and mice [31,32]. It has also been shown to attenuate the progression of vascular dysfunction in diabetic rats [31], protect hearts against diet- and STZ- induced metabolic changes and decrease infarct size after global I/R by increasing coronary flow [33], and mitigate cardiac dysfunction in abdominal aortic bandinginduced ventricular hypertrophy [34], indicating that CAPA may be beneficial in the treatment of diabetes and its cardiovascular complications.

The aim of this study was to characterize the effects of CAPA on I/R injury in normal and type 1 diabetic rats.

\section{Research design and methods}

\section{Chemicals}

Sodium pentobarbital, STZ, N $\omega$-nitro-L-arginine methyl ester (L-NAME), thiobutabarbital sodium salt hydrate (Inactin ${ }^{\circ}$ salt hydrate), methylene blue, 2,3,5-triphenyltetrazolium chloride (TTC), and poly-ethylene glycol 400 (PEG400) were purchased from Sigma-Aldrich, MO, USA. The chemicals for the physiological buffer were purchased from J.T. Baker, Capital Scientific Inc. and Wako Pure Chemical Industries. CAPA and 3,4-dimethoxyl caffeic acid phenethyl amide (dmCAPA, Figure 1) were synthesized and obtained from Institute of Chemistry, National Taiwan University [31]. CAPA was dissolved in PEG400 $30 \%$ for intraperitoneal injection or suspended in distilled water for oral administration.

\section{Animals and the induction of diabetic rats}

Eight-week-old male Sprague-Dawley rats (BioLASCO Taiwan, Co., Ltd, Taipei, Taiwan) weighing 250-300 g (bred in a Lab Animal Center, National Taiwan University,

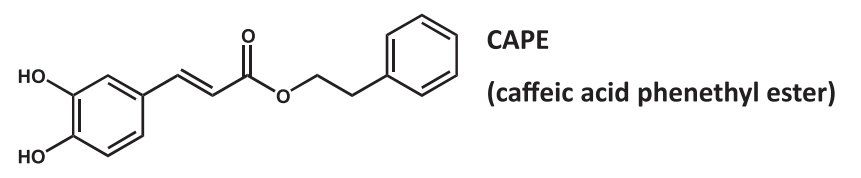<smiles>O=C(/C=C/c1ccc(O)c(O)c1)NCCc1ccccc1</smiles><smiles>COc1ccc(/C=C/C(=O)NCCc2ccccc2)cc1OC</smiles>

dmCAPA 
Taiwan) were used. The animals were housed in a conditioned environment $\left(22 \pm 1^{\circ} \mathrm{C}, 55 \pm 5 \%\right.$ relative humidity, 12-h light and darkness cycle, free access to food and water). Throughout the studies, all efforts were made to minimize animal pain and suffering. All animal procedures were performed according to the Guide for the Care and Use of Laboratory Animals of the National Institutes of Health, as well as the guidelines of the Animal Welfare Act, and the animal studies were approved by the Institutional Animal Care and Use Committee of the College of Medicine, National Taiwan University (certificate no. 20110073).

To evaluate the effects of CAPA on infarct size in healthy rats, the left anterior descending coronary artery (LAD) of 8-week-old rats was occluded for $45 \mathrm{~min}$ and reperfused for 2 hours; CAPA and AmCAPA were given intraperitoneally $30 \mathrm{~min}$ before reperfusion, while the nitric oxide synthase (NOS) inhibitor was given $15 \mathrm{~min}$ before CAPA and dmCAPA administration (Figure 2, panel 1).

For the induction of diabetes, fasting rats were anesthetized with sodium pentobarbital $(30 \mathrm{mg} / \mathrm{kg})$ and intravenously injected with STZ $(60 \mathrm{mg} / \mathrm{kg}$ freshly dissolved in sterile, non-pyrogenic $0.9 \% \mathrm{NaCl}$ solution in a volume of $1 \mathrm{~mL} / \mathrm{kg}$ body weight [35]) through the tail vein after a 72-h fast [36]. Two weeks after the STZ injection, the animals were considered to have type 1 diabetes if the plasma glucose level was $>350 \mathrm{mg} / \mathrm{dL}$ and diabetic features such as polyuria, polydipsia, and hyperphagia were observed [37].
Four weeks after the STZ induction, the animals were divided into three groups: age-matched non-diabetic control animals; STZ-diabetic rats administered vehicle (distilled water) for 4 weeks; and, STZ-diabetic rats administered CAPA (1 mg/kg/day) for 4 weeks (Figure 2, panel 2).

\section{Surgical procedure of $\mathrm{I} / \mathrm{R}$ injury in rat heart}

Rats underwent myocardial ischemia by the temporary occlusion of the LAD close to its origin to induce $I / R$ injury as previously described [38]. Briefly, the rats were intraperitoneally anesthetized with Inactin ${ }^{\circ}$ hydrate $(80 \mathrm{mg} / \mathrm{kg})$ and urethane $(4 \mathrm{~g} / \mathrm{kg})$ [39] on an operating table equipped with a heater to maintain the proper temperature. After undergoing a tracheotomy, the animals were ventilated with room air by a rodent ventilator (Model 683, Harvard Apparatus, South Natick, MA, USA) with a stroke volume of $10 \mathrm{~mL} / \mathrm{kg}$ body weight at a rate of 65 strokes $/ \mathrm{min}$. The chest was opened and the ribs were gently spread. The heart was quickly expressed out of the thoracic cavity, and a 7/0 silk ligature was placed under the LAD. The heart was repositioned in the chest and the animal was allowed to recover for $20 \mathrm{~min}$. A small plastic snare formed from a polyethylene tubing Portex P-270 cannula was threaded through the ligature and placed in contact with the heart. The ligature was tightened to occlude the artery and reperfusion was initiated by withdrawal of the polyethylene tubing. Regional myocardial ischemia was verified by the presence of a cyanotic zone in the area of distribution of the occluded vessel and by

Panel 1

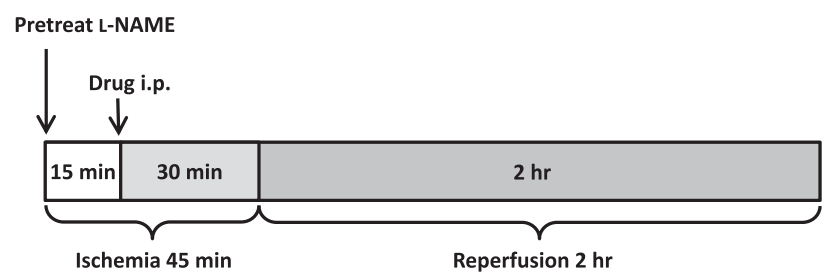

Panel 2

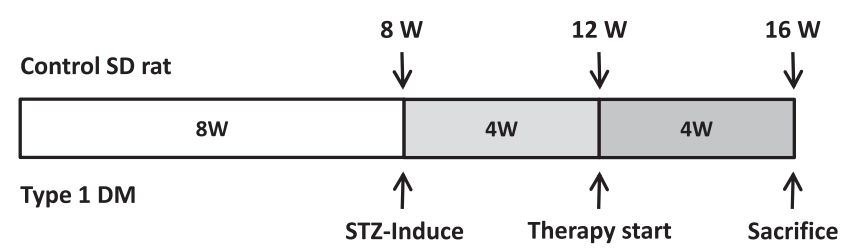

Figure 2 Ischemia/reperfusion model and chronic treatment time course in type 1 diabetic rats. All animals underwent coronary artery occlusion for $45 \mathrm{~min}$ followed by 2 hours of reperfusion. CAPA (3 and $15 \mathrm{mg} / \mathrm{kg}$ ) and dmCAPA (15 mg/kg) were administered intraperitoneally 30 min before reperfusion while the NOS inhibitor (L-NAME; $3 \mathrm{mg} / \mathrm{kg}$, intraperitoneal) was given before LAD occlusion (panel 1). For chronic treatment, type 1 diabetes was induced by STZ over 4 weeks in 8-week-old rats that were then treated with vehicle or CAPA for 4 weeks (panel 2) 
changes in the electrocardiogram consistent with the presence of transmural regional myocardial ischemia (ST-segment elevation).

\section{Estimation of myocardial damage}

At the end of the experiment, the ischemic and perfused areas of heart were determined by injection of methylene blue $(2 \mathrm{~mL} ; 0.2 \%$ in $0.9 \% \mathrm{NaCl})$ through the jugular vein after coronary artery re-occlusion. The rat was sacrificed and the heart was differentiated into perfused (blue) and occluded regions. The occluded region (defined as the "area at risk" [AAR]) was cut out, weighed, and expressed as a percentage of ventricle weight. Thereafter, the occluded tissue was sliced into l-mm sections for incubation in TTC (in saline, $1 \%$ ) at $37^{\circ} \mathrm{C}$ for $30 \mathrm{~min}$. The sections were placed in $10 \%$ formaldehyde in saline for 2 days. The infarcted (white) tissue was excised and weighed. Infarct size was expressed as a percentage of weight in the occluded zone [40].

\section{Tissue malondialdehyde (MDA) content analysis}

The unperfused zone of cardiac tissue was collected as described above for the determination of MDA content using a commercial kit from Sigma-Aldrich Co. LLC (Catalog Number MAK085). Briefly, tissue samples were homogenized in phosphate-buffered saline solution and then completely homogenized by ultra-sonication $(40 \mathrm{~V}$ for $15 \mathrm{~s}$ ). The supernatants were collected in glass tubes and reacted with sodium acetate solution containing thiobarbituric acid (TBA) at $95^{\circ} \mathrm{C}$ for $60 \mathrm{~min}$. After centrifugation, the supernatants were collected and the resulting TBA-reactive substances were measured spectrophotometrically at $532 \mathrm{~nm}$ absorbance and expressed as MDA equivalents (nmol) per milligram of wet tissue as a measure of lipid peroxidation [41].

\section{Tissue myeloperoxidase (MPO) activity analysis}

The occluded zone of cardiac tissue was collected as described above for the determination of MPO activity using a commercial kit from Sigma-Aldrich Co. LLC (Catalog Number MAK068). Briefly, tissue samples were homogenized in hexadecyl trimethyl ammonium bromide and dissolved in potassium phosphate. After centrifugation, the supernatants were collected and mixed with $o$-dianisidine hydrochloride and hydrogen peroxide in phosphate buffer. MPO activity was measured spectrophotometrically at $412 \mathrm{~nm}$ absorbance. MPO activity was defined as the quantity of enzyme degrading $1 \mathrm{mmol}$ of peroxide per min at $37^{\circ} \mathrm{C}$ and was expressed in units per milligram of wet tissue as a measure of neutrophil activation [40].

\section{Physiological hemodynamic parameters recording}

Polyethylene catheters (PE 50) were inserted into the common carotid artery of the rats to measure blood pressure and the three-lead electrodes were inserted subcutaneously to monitor the electrocardiography. The arterial blood pressure and electrocardiography data were continuously recorded by a PowerLab 4/30 data acquisition system (ADInstruments, Castle Hill, NSW, Australia), while the cardiac function was assessed by a pressure and volume microtip catheter (1.9 F; Scisense Instruments, Ontario, Canada). This catheter was inserted into the left ventricle to measure pressure and volume. The pressure was measured at a sampling rate of $1,000 / \mathrm{s}$ using a PONEMAH real-time acquisition interface P3P Plus coupled to an analog-to-digital converter (ACQ-16). All pressure volume (PV) loop data were analyzed using the PONEMAH Life Sciences Suite cardiac PV analysis program from Data Sciences International (St. Paul, MN, USA). The hemodynamic parameters included left ventricle end-systolic pressure (LVESP), LV end-diastolic pressure (LVEDP), stroke volume (SV), maximum positive value $(+\mathrm{dP} / \mathrm{dt})$, maximum negative value $(-\mathrm{dP} / \mathrm{dt})$ of the first derivative of the pressure, stroke work (SW), and ejection fraction. The preload-independent cardiac contractility parameters were also determined under conditions of changing preload, elicited by transient compression of the abdominal inferior vena cava. These measurements include end-systolic pressure volume relationship (ESPVR), end-diastolic pressure volume relationship (EDPVR), and the preload recruitable stroke work (PRSW). In addition, arterial volume elastance (Ea) was calculated as the ratio of LVEDP at the point in the cycle where the PV ratio peaks versus the stroke volume under different experimental conditions [42].

\section{Data analysis}

Values are expressed as mean \pm standard error of mean (SEM). The data were subjected to one-way analysis of variance followed by a multiple-comparison test (Bonferronitest). Values of $P<0.05$ were considered statistically significant.

\section{Results \\ CAPA protected the heart from I/R injury via a nitric oxide (NO)-dependent pathway}

To investigate the cardioprotective effects of CAPA against $\mathrm{I} / \mathrm{R}$ injury in vivo, rats were intraperitoneally treated with CAPA (3 and $15 \mathrm{mg} / \mathrm{kg}$ ) or dmCAPA (CAPA derivative, methylation at the hydroxyl groups, no antioxidant activity; $15 \mathrm{mg} / \mathrm{kg}$; Figure 1) $30 \mathrm{~min}$ before the reperfusion. Regional myocardial I/R was established by ligating the LAD of the rat heart for 45 minutes followed by reperfusion for 2 hours in vivo (Figure 2, panel 1). Hearts were analyzed by TTC to quantify the infarct size in the AAR. The AAR did not differ significantly among any of the groups of hearts (Figure 3A). The administration of $3 \mathrm{mg} / \mathrm{kg}$ and $15 \mathrm{mg} / \mathrm{kg}$ CAPA dose-dependently reduced I/R-induced 

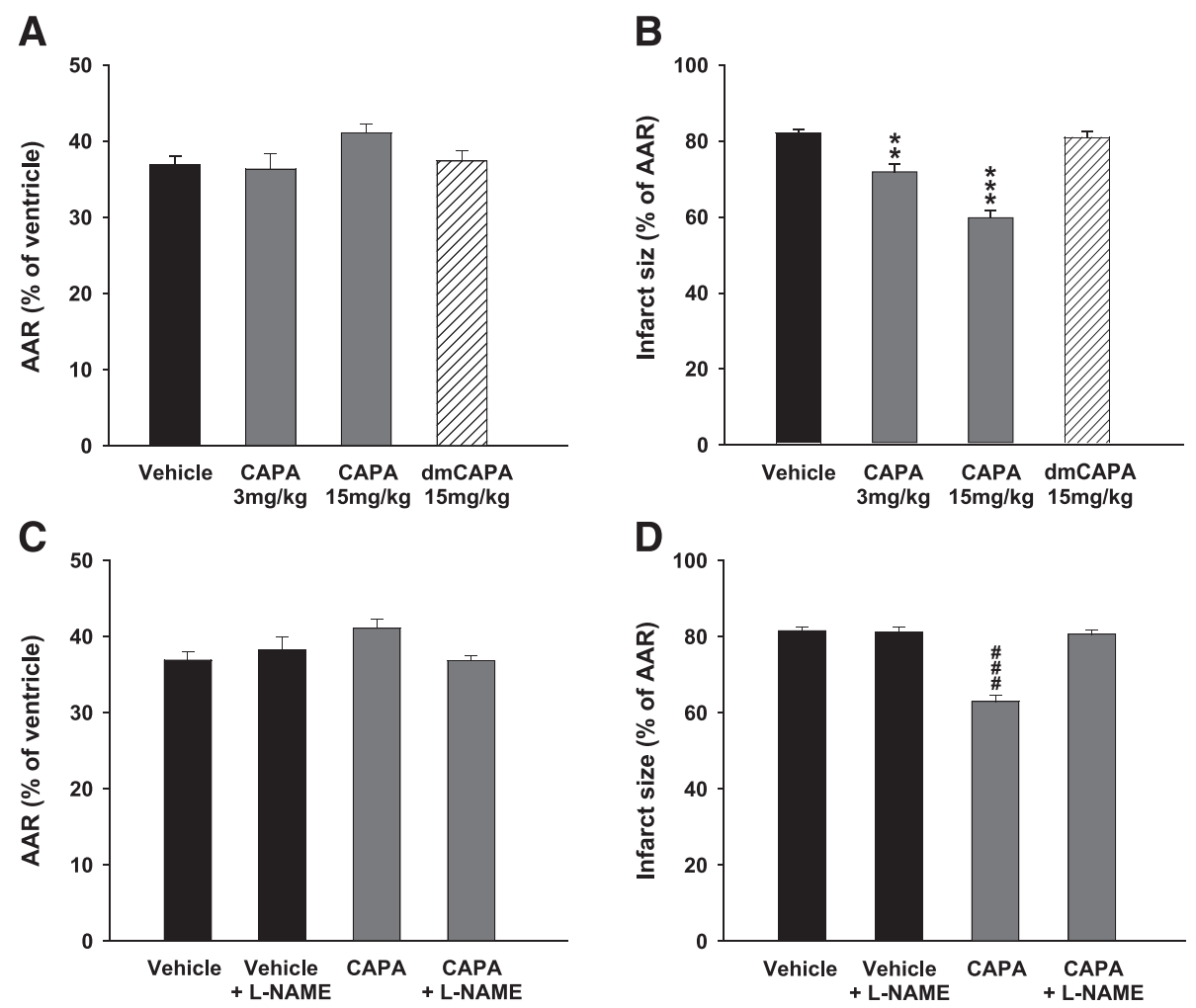

Figure 3 Effects of CAPA, dmCAPA and L-NAME pretreatment on I/R injury. (A) Area at risk (AAR; \% of ventricle) and (B) infarct size (\% of AAR) in control rats treated with vehicle and in rats treated with CAPA ( 3 or $15 \mathrm{mg} / \mathrm{kg})$ and $\mathrm{dmCAPA}(15 \mathrm{mg} / \mathrm{kg}) .{ }^{* *} P<0.01 \mathrm{and}$ ${ }^{* *} P<0.001$ compared to vehicle. (C) AAR (\% of ventricle) and (D) infarct size (\% of AAR) in control rats treated with vehicle and in rats pretreated with L-NAME $(3 \mathrm{mg} / \mathrm{kg})$ and treated with CAPA $(15 \mathrm{mg} / \mathrm{kg}) .{ }^{\# \# \#} P<0.001$ compared to vehicle. Data (mean \pm SEM) were obtained from 6-8 animals.

infarct size from $81.5 \%$ in control hearts to $70.2 \%(P<0.01)$ and $62.9 \%(P<0.001)$, respectively. However, dmCAPA had no effect on infarct size (Figure $3 \mathrm{~B}$ ).

On the other hand, pretreatment with the NOS inhibitor (L-NAME $3 \mathrm{mg} / \mathrm{kg}$ ) could effectively abolish the effect of CAPA on infarct size without changing AAR (Figures $3 \mathrm{C}$ and D).

\section{CAPA decreased the MDA content and MPO activity in I/R} injury

We evaluated the effects of CAPA on lipid peroxidation and neutrophil activation by evaluating MDA content and MPO activity, respectively. CAPA administration $(15 \mathrm{mg} / \mathrm{kg}$ ) significantly reduced MDA content compared to vehicle $(P<0.05$; Figure $4 \mathrm{~A})$, which means that
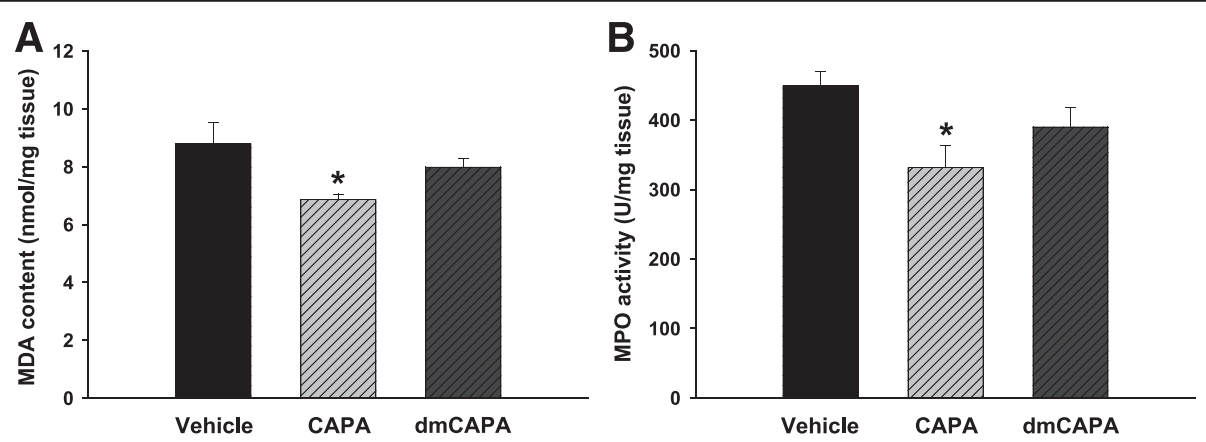

Figure 4 Effects of CAPA treatment on MDA levels and MPO activity. We administered CAPA (15 mg/kg, $n=10)$ and dmCAPA (15 mg/kg, $n=5$ ) after 45 minutes of LAD ligation followed by 2 hours of reperfusion. After $I / R$, the tissue in the area at risk was collected for measurement of MDA levels (A) and MPO activity (B). ${ }^{*} P<0.05$ compared with controls. 
CAPA could reduce the oxidative stress level in the heart during I/R. Moreover, CAPA could reduce MPO activity compared to vehicle $(P<0.05$; Figure $4 \mathrm{~B})$. However, neither MDA content nor MPO activity significantly reduced with the same dosage of dmCAPA.

\section{The chronic effect of CAPA on body weight and heart weight in diabetic rats}

To investigate the effects of chronic CAPA treatment on cardiac function in diabetic rats, the STZ-induced type 1 diabetic rats were divided into two groups: one group treated with vehicle (distilled water) and a second group treated with CAPA ( $1 \mathrm{mg} / \mathrm{kg}$, orally). After 4 weeks, both body weight and heart weight of vehicle-treated diabetic animals were lower than those of the age-matched animals $(244.2 \pm 12.8 \mathrm{~g}$ and $0.83 \pm 0.03 \mathrm{~g}$ vs. $468.5 \pm 6.1 \mathrm{~g}$ and $1.27 \pm 0.02 \mathrm{~g}, P<0.001$; Figures $5 \mathrm{~A}$ and B). CAPA treatment did not affect body weight or heart weight of diabetic animals $(265.7 \pm 19.7 \mathrm{~g}$ and $0.93 \pm 0.06 \mathrm{~g}$, respectively). However, the ratio of heart weight to body weight was higher in both diabetic groups treated with vehicle and CAPA $(0.34 \pm 0.03$ and $0.35 \pm 0.02$, respectively) than in the control group $(0.27 \pm 0.01, P<0.001$; Figure 5C).

\section{CAPA increased heart rate and mean blood pressure during the $\mathrm{I} / \mathrm{R}$ period in diabetic rats}

The mean heart rates of STZ-vehicle diabetic rats at the time before (BS 0), $45 \mathrm{~min}$ after ischemia (IS 45), and 60 min after reperfusion (RP 60) were significantly lower than those of age-matched control $(290.9 \pm 11.2 \mathrm{bpm}$, $253.2 \pm 11.9 \mathrm{bpm}$, and $233.0 \pm 11.3 \mathrm{bpm}$ vs. $367.9 \pm$ $16.3 \mathrm{bpm}, 316.1 \pm 16.2 \mathrm{bpm}$, and $308.2 \pm 23.3 \mathrm{bpm}$, respectively; Figure 6A). CAPA treatment reversed the decrease in heart rate in diabetic rats, especially at the time point of IS 45 compared to the STZ-vehicle group $(302.5 \pm 9.1 \mathrm{bpm}, P<0.05)$. Similarly, the mean blood pressure was lower in STZ-vehicle diabetic rats than in control rats $60 \mathrm{~min}$ after reperfusion $(52.3 \pm 3.1 \mathrm{mmHg}$ vs. $64.6 \pm 4.7 \mathrm{mmHg}$ ), but CAPA could significantly ameliorate this effect $(65.0 \pm 4.2 \mathrm{mmHg}, P<0.05$; Figure 6B).

\section{CAPA decreased the infarct size after I/R in diabetic rats}

Eight weeks after the STZ induction, the area at risk was similar among control, STZ-vehicle and STZ-CAPA diabetic rats (Figure 7A), while the infarct size was significantly increased in the STZ-vehicle diabetic animals $(58.3 \pm 2.3 \%$ vs. $45.1 \pm 4.3 \%$ in age-matched normal rats,
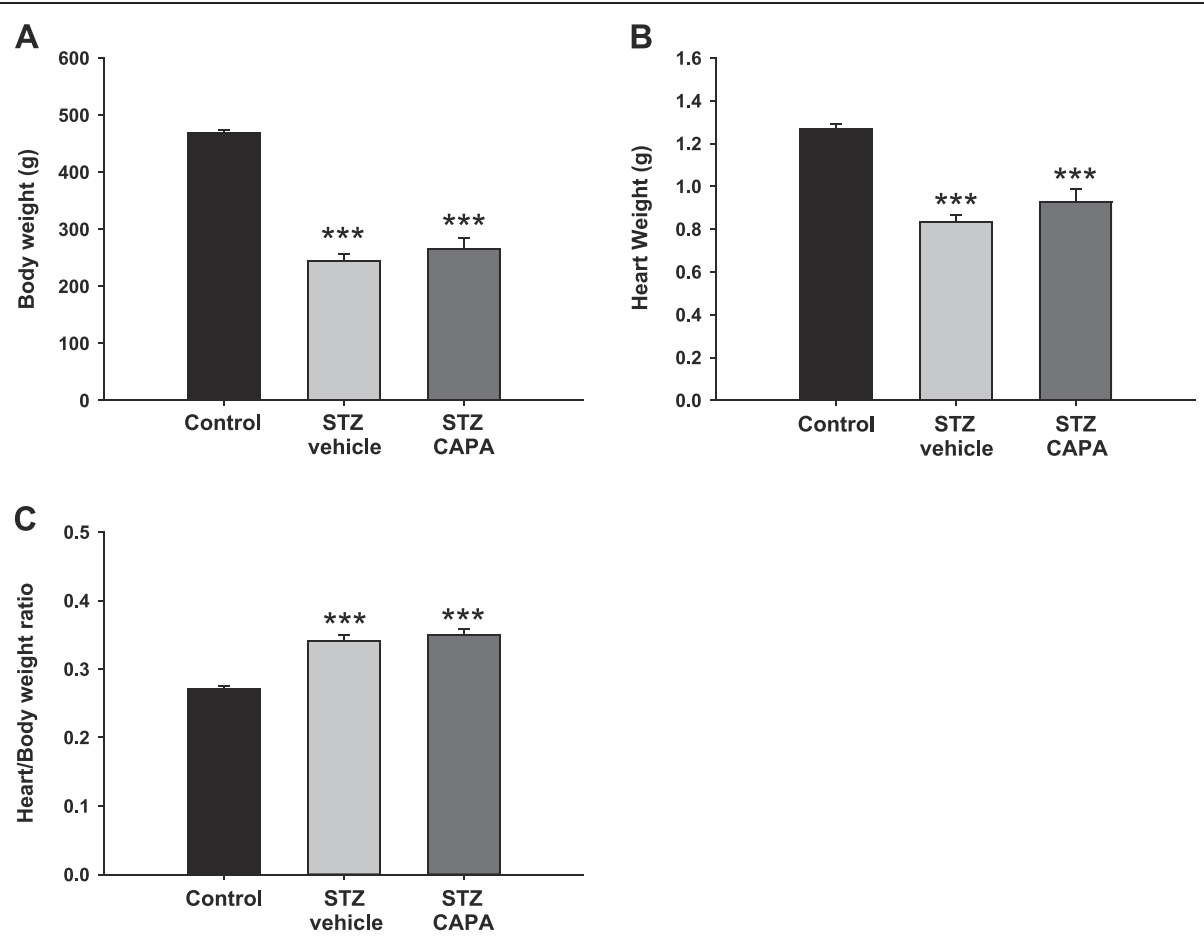

Figure 5 Effects of CAPA treatment on body weight and heart weight. After I/R, the body weight (A), heart weight (B), and heart/body weight ratio (C) were calculated. For chronic treatments, the animals were divided into three groups: control, age- and sex-matched normal rats, $\mathrm{n}=16$; STZ-vehicle, age- and sex-matched diabetic animals administered distilled water orally for 4 weeks starting 4 weeks after STZ induction, $\mathrm{n}=13$; and STZ-CAPA, CAPA $1 \mathrm{mg} / \mathrm{kg}$ administered orally once daily for 4 weeks starting 4 weeks after STZ induction, $\mathrm{n}=6$. Data are expressed as mean \pm SEM. ${ }^{* * *} P<0.001$ compared with control group. 

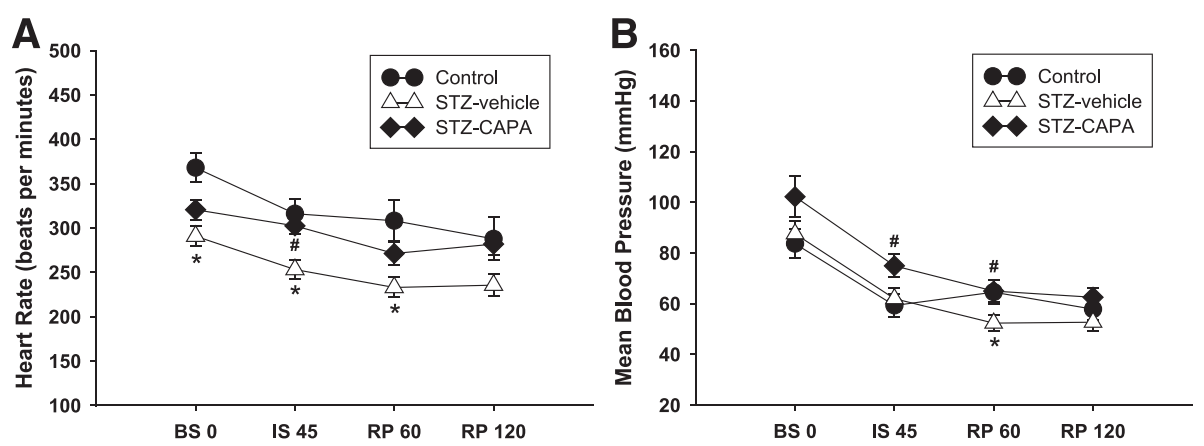

Figure 6 Effects of CAPA treatment on heart rate and mean blood pressure in diabetic rats. The heart rate (A) and mean blood pressure (B) during the I/R period in control and diabetic rats were recorded. For chronic treatments, the animals were divided into three groups: control, age- and sex-matched normal rats, $n=16$; STZ-vehicle, age- and sex-matched diabetic animals administered distilled water orally for 4 weeks starting 4 weeks after STZ induction, $\mathrm{n}=13$; and STZ-CAPA, CAPA $1 \mathrm{mg} / \mathrm{kg}$ administered orally once daily for 4 weeks starting 4 weeks after STZ induction, $n=6$. BS 0, basal value just before ischemia; IS 45, 45 min after ischemia but just before reperfusion; RP 60,60 min after reperfusion; RP 120, 120 min after reperfusion. Data are expressed as mean \pm SEM. ${ }^{*} P<0.05$ compared with control group and ${ }^{\#} P<0.05$ compared with STZ-vehicle group.

* $P<0.05)$. Chronic treatment of CAPA could decrease the infarct size to $30.1 \pm 8.7 \%\left({ }^{\#} P<0.05\right.$; Figure $\left.7 \mathrm{~B}\right)$.

\section{CAPA ameliorated I/R-induced cardiac dysfunction in diabetic rats on PV loop analysis}

The cardiac functions of control, STZ-vehicle, and STZCAPA diabetic rats were measured by pressure-volume loops before and after I/R. The PV loops are derived from LV pressure versus LV volume in the cardiac cycle diagram by transiently compressing the abdominal inferior vena cava (Figure 8).

The maximum velocity of both contraction and relaxation in STZ-vehicle diabetic rats were significantly lower than those of age-matched control rats before $I / R$ $(6895.5 \pm 393.9 \mathrm{mmHg} / \mathrm{s}$ and $5485.0 \pm 276.6 \mathrm{mmHg} / \mathrm{s}$ vs. $9120.2 \pm 634.5 \mathrm{mmHg} / \mathrm{s}$ and $7195.4 \pm 450.1 \mathrm{mmHg} / \mathrm{s}$, $P<0.05$; Figures $9 \mathrm{~A}$ and $\mathrm{B})$. CAPA treatment did not reverse the decrease in the maximum rate of relaxation but seemed to have the activity to reverse the decrease in the maximum rate of contraction in STZ-diabetic rats. However, there were no significant differences among any of the groups after I/R.

In LVESP, there were no differences among any of the groups before or after I/R (Figure 9C), but the mean LVEDP values of the diabetic groups were higher than that of the control group at baseline $(12.7 \pm 1.4$ and $12.8 \pm 2.1 \mathrm{mmHg}$ in the STZ-vehicle and STZ-CAPA groups compared to $7.5 \pm 0.7 \mathrm{mmHg}$ in the control group, $P<0.05$; Figure 9D).

Figure 9E shows that the ejection fraction significantly decreased in STZ-vehicle diabetic rats before and after I/R compared to the control group $(48.0 \pm 3.0 \%$ and $51.0 \pm 8.4 \%$ vs. $70.6 \pm 3.4 \%$ and $69.8 \pm 12.0 \%$, respectively). CAPA treatment reversed the decrease before $I / R$
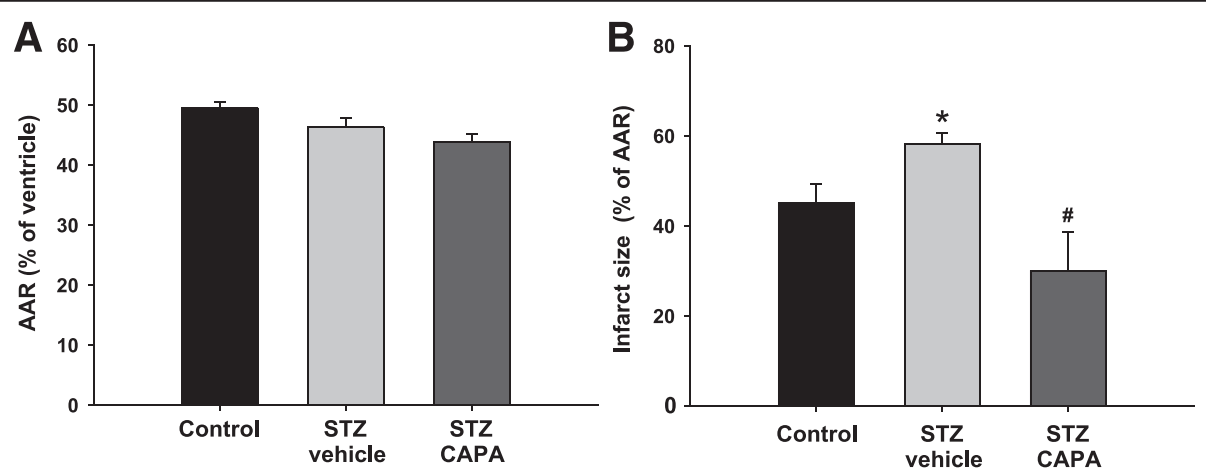

Figure 7 Effects of CAPA treatment on infarct size in diabetic rats. After I/R injury, area at risk (A) and infarct size/area at risk ratio (B) in diabetic rats were calculated. For chronic treatments, the animals were divided into three groups: control, age- and sex-matched normal rats, $\mathrm{n}=16$; STZ-vehicle, age- and sex-matched diabetic animals administered distilled water orally for 4 weeks starting 4 weeks after STZ induction, $\mathrm{n}=13$; and STZ-CAPA, CAPA $1 \mathrm{mg} / \mathrm{kg}$ administered orally once daily for 4 weeks starting 4 weeks after STZ induction, $\mathrm{n}=6$. Data are expressed as mean \pm SEM. ${ }^{*} P<0.05$ compared with control group and ${ }^{\#} P<0.05$ compared with STZ-vehicle group. BS 0 , basal value just before ischemia; IS 45 , 45 min after ischemia but just before reperfusion; RP 60, 60 min after reperfusion; RP 120, 120 min after reperfusion. 


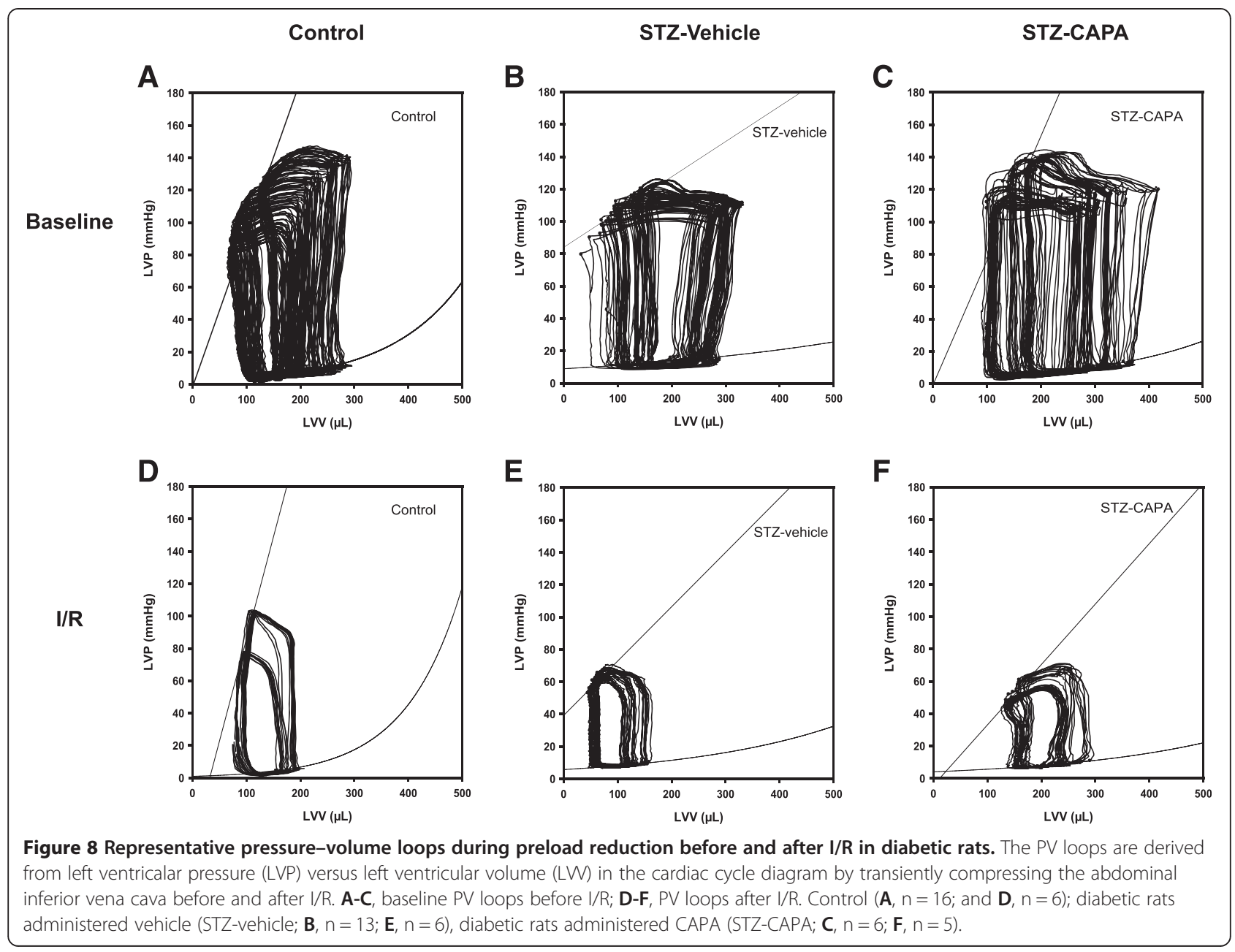

$(69.0 \pm 6.6 \%, P<0.05$; Figure 9E), but not after reperfusion $(42.8 \pm 7.2 \%)$. There were no significant changes in stroke volume or stroke work among any of the groups before or after I/R except that STZ-CAPA diabetic rats had a higher mean stroke work value than the STZ-vehicle diabetic group (17785.4 \pm 1206.4 vs. $12498.6 \pm 902.3 \mathrm{mmHg} \times \mu \mathrm{L}$, $P<0.05$; Figures $9 \mathrm{~F}$ and $\mathrm{G})$.

In addition to the above parameters, PV loops at different preloads could be used to derive several preloadindependent parameters. At baseline, ESPVR, EDPVR, and PRSW were lower in the STZ-vehicle group than in the control group $(0.40 \pm 0.04 \mathrm{mmHg} / \mu \mathrm{L}, 0.0037 \pm 0.0012 \mathrm{mmHg} / \mu \mathrm{L}$, and $47.8 \pm 5.3 \mathrm{mmHg}$ vs. $1.14 \pm 0.40 \mathrm{mmHg} / \mu \mathrm{L}, 0.0097 \pm$ $0.0012 \mathrm{mmHg} / \mu \mathrm{L}$, and $85.5 \pm 5.3 \mathrm{mmHg}$, respectively; Figures 9I, J, and K), but only ESPVR and PRSW were significantly reversed in the STZ-CAPA group (1.17 \pm $0.30 \mathrm{mmHg} / \mu \mathrm{L}$ and $82.2 \pm 6.5 \mathrm{mmHg}$ ).

\section{Discussion}

The antioxidant effect of CAPA on I/R injury

Myocardial infarction usually results from thrombus [43], vasospasm [44], routine coronary angioplasty [45], or open-heart operation [46]. Although restoration of blood flow is the only way to save the myocardium from ischemic injury, reperfusion can exacerbate the myocardial damage caused by ischemia. The mostly recognized cause of reperfusion injury is a burst of free radicals including hydrogen peroxide, hydroxyl radical, and superoxide radical that is formed during reperfusion and plays an important role in the pathophysiological mechanism of $I / R$ injury [4]. Moreover, treatment with antioxidant remedies or agents capable of inducing antioxidant enzymes such as glutathione peroxidase and superoxide dismutase have a cardioprotective effect against $I / R$ injury in experimental animals in vivo and in vitro [47]. Therefore, antioxidant therapy may be an effective process for treating myocardial infarction. However, predicting when myocardial infarction occurs and preventing the infarction with longterm antioxidants use is impractical, and administering medications after ischemia and before reperfusion is a more reasonable way to treat patients with myocardial infarction. Therefore, we administered CAPA $30 \mathrm{~min}$ prior to reperfusion to evaluate the cardiac effect of CAPA in I/R. The 2,2-diphenyl-1-picrylhydrazyl radical scavenging activity 

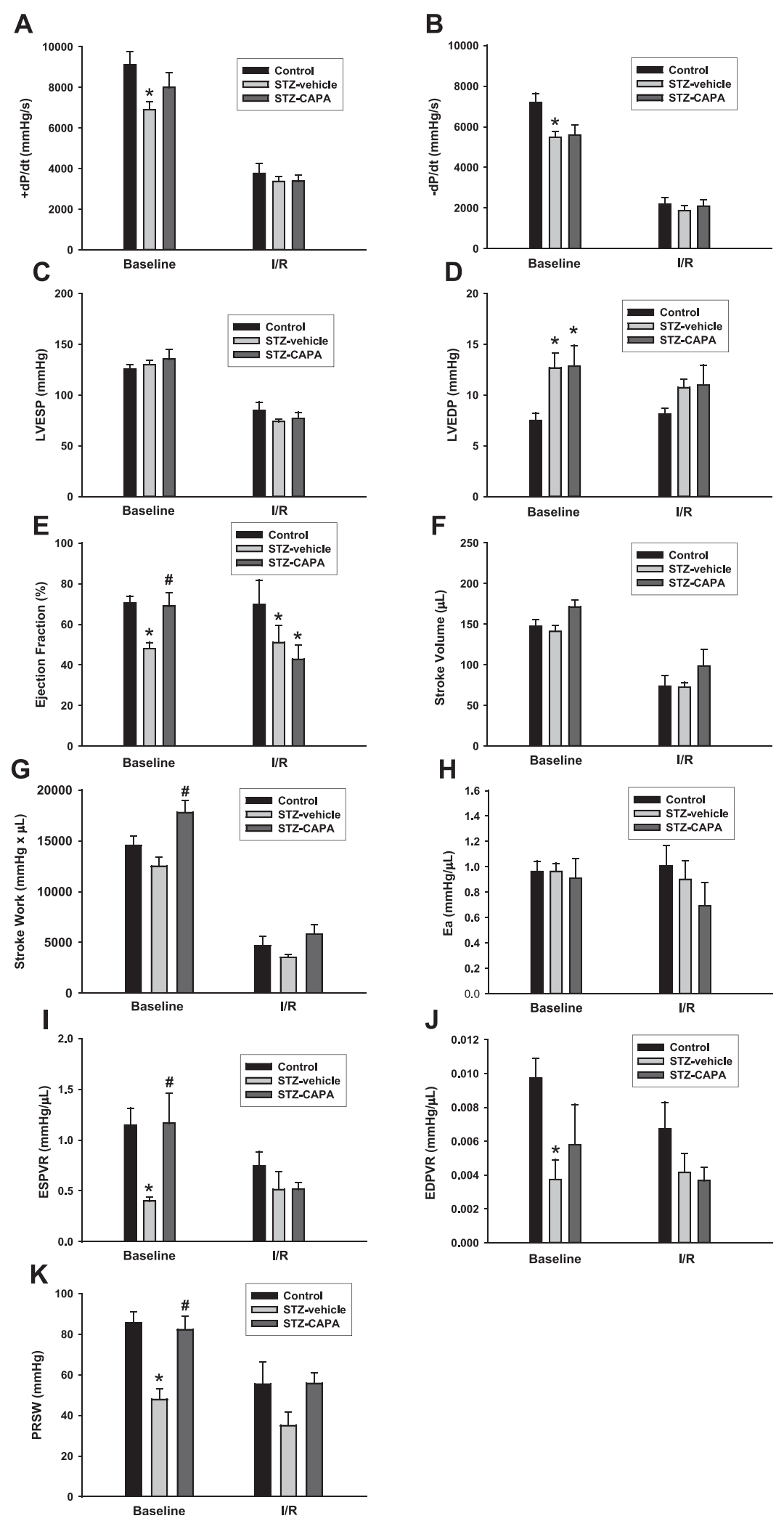

Figure 9 (See legend on next page.) 

relationship (EDPVR, J). Preload recruitable stroke work (PRSW, K). All values are represented as mean \pm SEM before (baseline) and after I/R (I/R). ${ }^{*} P<0.05$ compared to age- and sex-matched non-diabetic control rats. ${ }^{~} P<0.05$ versus age- and sex-matched diabetic rats treated with vehicle.

of CAPA, as shown by an $\mathrm{EC}_{50}$ of $18.6 \pm 3.2 \mu \mathrm{M}$ (comparable to the $\mathrm{EC}_{50}$ of $15.6 \pm 2.0 \mu \mathrm{M}$ CAPE, data not shown), was in accordance with that seen in other studies of the structure action relationship of CAPE and CAPA [26,48] and may reduce tissue oxidative stress and increase tissue availability of NO. In addition, our studies in type 2 diabetic mice have shown that CAPA treatment could increase manganese superoxide dismutase in fat tissue [33], but whether this effect is involved in improving the hemodynamic function of STZ-induced diabetic rats remains unknown.

CAPE administration protected the heart from I/R injury with reduced levels of oxidative stress such as MDA [21]. In our study, CAPA administration reduced MDA to a level comparable to that seen in the control group. An analog of CAPA, dmCAPA, which has no radicalscavenging activity, exhibited no cardioprotective effect on infarct size, suggesting that CAPA, like CAPE, exerts a cardioprotective effect mainly through its antioxidant property. Compared with vehicle treatment, the MPO activity reduced with CAPA administration, but not with dmCAPA. This finding suggests that the cardioprotective effect of CAPA could be partly attributed to the reduced inflammatory response by its antioxidant ability.

\section{NO preservation effect of CAPA on I/R injury}

Although the role of NO remains controversial, myocardial I/R injury is exacerbated in the absence of endothelial cell NOS [49]; and endothelial NOS is able to regulate vascular tension [50], inhibit platelet aggregation [51], scavenge ROS, and stimulate endothelial regeneration to protect the heart and blood vessels [52]. CAPA inhibited lipopolysaccharide/interferon- $\gamma$ (LPS/IFN- $\gamma$ )-induced inducible NOS (iNOS) expression and NO production [53], while a CAPA-induced increase in coronary blood flow was prevented by a NOS inhibitor, which suggests that CAPA may enhance coronary blood flow by increasing NO availability or level [31]. In our study, pretreatment with the NOS inhibitor L-NAME eliminated the cardioprotective effect of CAPA on infarct size reduction, suggesting that $\mathrm{NO}$ is an important factor responsible for cardioprotection. We propose that the cardioprotective effect of CAPA resulted from its own antioxidant property, which preserves the bioavailable NO in the heart. However, this assumption requires further supported by more direct evidence.

\section{Effect of chronic CAPA treatment on cardiac dysfunction in diabetes}

Animals with STZ-induced diabetes showed reduced resting heart rate and pulse pressure [54]. In our study, the heart rate of diabetic rats was significantly lower than that of control rats during the I/R period, while CAPA treatment reversed the reduction after $45 \mathrm{~min}$ of ischemia (Figure 6A). The mean blood pressures of the CAPA-treated groups were higher than those of the other two groups when the hearts were subjected to ischemia for $45 \mathrm{~min}$ and higher than those of the STZ-diabetic animals after $60 \mathrm{~min}$ of reperfusion (Figure 6B). The pressure preservation effect was in accordance with that seen in our earlier study concluding that CAPA may preserve the vasomotor activity in diabetic animals [31]. The maintenance of blood pressure and heart rate by chronic CAPA treatment may contribute to its protective effect against $I / R$ injury in diabetic animals.

The STZ-induced diabetic animals underwent hemodynamic changes in cardiac function measured by PV loops [55-57]. In our study, the $\mathrm{dP} / \mathrm{dt} \max , \mathrm{dP} /$ $\mathrm{dt}$ min, ejection fraction, ESPVR, EDPVR, and PRSW values were decreased and the LVEDP value was increased in the STZ-vehicle group; in agreement with the wellestablished model of STZ-induced diabetic cardiomyopathy. Compared with the STZ-vehicle group, CAPA treatment preserved the basal cardiac function in terms of PRSW, ESPVR, and ejection fraction, but slight preservation of PRSW and stroke work occurred after I/R injury. CAPA treatment did not reverse any parameters of hemodynamic function after reperfusion; however, the ameliorations of these parameters at baseline may contribute to the reduction of infarct size after I/R.

\section{The underlying mechanisms of CAPA against cardiac dysfunction in diabetes}

There are several mechanisms involved in the development of diabetic cardiomyopathy, including increased oxidative stress, and activation of the renin-angiotensin system [58].

In the STZ-induced diabetic rats subjected to I/R injury, hyperglycemia, an independent risk factor, worsens cardiac performance, cell survival, and tissue injury following myocardial $\mathrm{I} / \mathrm{R}$ via increased oxidant production and reduced antioxidant defenses [2,3,59]. In our study, CAPA ameliorated the $I / R$ injury, but this protective 
effect disappeared when the $-\mathrm{OH}$ functional groups were substituted with methoxyl groups, and the antioxidant activity of CAPA may contribute to the protective effect on the I/R injury and cardiac dysfunction in diabetes.

Intracellular angiotensin II was proven to have a significant role in the pathological process in $\mathrm{AT}_{1 \mathrm{a}}$ receptordeficient diabetic mice. The inhibition of intracellular angiotensin II level by a renin or angiotensin-convertingenzyme inhibitor prevented the development of cardiac dysfunction in these diabetic mice [60]. AT-1 receptor antagonists attenuate cardiac failure by decreasing cardiac inflammation and normalizing matrix metalloproteinase activity, leading to the alleviation of cardiac fibrosis in STZ-induced diabetic cardiomyopathy [56]. The inhibition of Rho-kinase protects the cerebral barrier from ischemiaevoked injury by modulating endothelial cell oxidative stress and tight junctions [61] and protects the structure and function of cardiac mitochondria from diabetes by attenuating oxidative stress [62]. Acute Rho-kinase inhibition improves coronary dysfunction in vivo in the early diabetic microcirculation [63], while long-term Rho-kinase inhibition ameliorates myocardial hypertrophy, apoptosis, fibrosis, and subsequent cardiac remodeling in diabetes [64]. The Rho-associated protein kinase-mediated signaling pathway is known to be involved in the vascular effects of angiotensin II [65], and renin-angiotensin system blockade is beneficial to the cardiovascular system and a known treatment for diabetic cardiomyopathy [66]. In our earlier study, we found that CAPA decreased plasma angiotensin II level in mice with abdominal aortic banding-induced ventricular hypertrophy [34], implicating that the angiotensin II-lowering activity of CAPA may protect the cardiovascular function in diabetes. The level of iNOS is associated with the induction of RhoA expression in the hearts of diabetic rats [67], while CAPA inhibits LPS/IFN- $\gamma$-induced iNOS expression [53], implicating that the inhibition of iNOS expression may contribute to its protection against diabetic cardiomyopathy.

Recent evidence shows that an increased infarct size is associated with low levels of myocardial heme oxygenase1 (HO-1) during I/R in diabetic rats [2,3]. The nuclear factor erythroid 2-related factor 2 (Nrf2) signaling pathway regulates the oxidative stress response, and altered Nrf2 responses may contribute to the observed selective cytotoxicity of electrophilic compounds [68]. Nrf2 is a transcription factor that regulates the expression of many detoxification or antioxidant enzymes [69]. CAPE stimulates ho-1 gene activity by promoting inactivation of the Nrf2-Keap1 complex, leading to increased Nrf2 binding to the resident ho-1 AREs, and the induction of HO-1 by CAPE requires Nrf2/ARE pathway activation [70]. In HO-1 activation, CAPA was as effective as CAPE at inducing HO-1 mRNA (nine-fold over vehicle control) as determined by reverse transcription-polymerase chain reaction [71], and CAPA can induce HO-1 mRNA expression in rat primary cultured microglia [53]. These data indicate that CAPA treatment may mitigate infarction in diabetic rats by inducing $\mathrm{HO}-1$ activity.

\section{Conclusions}

STZ-induced diabetic animals suffer from deteriorated cardiac function with increased myocardial infarction following I/R. CAPA can reduce the infarct size after I/R injury, and this study demonstrated that long-term CAPA treatment reversed cardiac dysfunction in diabetic animals. The cardioprotective effect of CAPA may result from its antioxidant activity and the associated preservation of NO-dependent mechanisms. However, the mechanisms of cardiac function preservation in STZ-induced diabetic rats by 4 -week CAPA treatment remain to be investigated.

\section{Abbreviations}

$+\mathrm{dP} / \mathrm{dt}$ : Maximum positive value of the first derivative of the pressure; $-d P / d t:$ Maximum negative value of the first derivative of the pressure: AAR: Area at risk; bpm: Beats per minute; CAPA: Caffeic acid phenethyl amide; CAPE: Caffeic acid phenethyl ester; dmCAPA: Dimethoxyl caffeic acid phenethyl amide; Ea: Arterial volume elastance; EDPVR: End-diastolic pressure volume relationship; ESPVR: End-systolic pressure volume relationship; HO-1: Heme oxygenase-1; I/R: Ischemia-reperfusion; iNOS: Inducible nitric oxide synthase; LAD: Left anterior descending coronary artery;

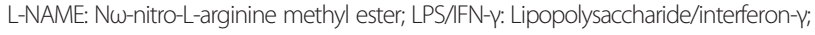
LV: Left ventricle; LVEDP: Left ventricle end-diastolic pressure; LVESP: Left ventricle end-systolic pressure; LVP: Left ventricular pressure; LW: Left ventricular volume; MDA: malondialdehyde; MPO: Myeloperoxidase; NO: Nitric oxide; NOS: Nitric oxide synthase; Nrf2: Nuclear factor enythroid 2-related factor 2; PEG400: Poly-ethylene glycol 400; PRSW: Preload recruitable stroke work; PV loop: Pressure-volume loop; ROS: Reactive oxygen species; SEM: Standard error of the mean; STZ: Streptozotocin; SV: Stroke volume; SW: Stroke work; TBA: Thiobarbituric acid;

TTC: 2,3,5-Triphenyltetrazolium chloride.

\section{Competing interests}

The authors declare that they have no competing interests.

\section{Authors' contributions}

Participated in research design: YJH, ASL, WPC, WLC and MJS; Conducted experiments: diabetic animal induction: YJH; I/R model: YJH and YKT; PV loop experiments and analysis: YJH, WPC and ASL; Synthesis, purification of CAPA and dmCAPA: HLC and YHK; Performed data analysis: YJH, ASL, WPC, WLC, YKT and MJS; Contributed to the writing of the manuscript: YJH, ASL, WPC, YKT, WLC and MJS; Directed the study and problem solving: MJS. All authors read and approved the final manuscript.

\section{Acknowledgements}

The source of financial support: This work were supported by National Science Council, Taiwan (NSC 98-2323-B-002-014-CC2, NSC 102-2325-B-002-056), Taiwan Department of Health Clinical Trial and Research Center of Excellence (DOH102-TD-B-111-004) and CMU under the Aim for Top University Plan of the Ministry of Education, Taiwan.

\section{Author details}

'Department of Pharmacology, College of Medicine, National Taiwan University, 11F, No. 1, Sec. 1, Jen-Ai Road, Taipei 10051, Taiwan. ${ }^{2}$ Department of Medicine, Mackay Medical College, New Taipei 252, Taiwan. ${ }^{3}$ Department of Chemistry, National Taiwan University, Taipei 100, Taiwan. ${ }^{4}$ Department of Chinese Pharmaceutical Sciences and Chinese Medicine Resources, China Medical University, Taichung 404, Taiwan. ${ }^{5}$ Department of Biotechnology, Asia University, Taichung 413, Taiwan. 
Received: 4 April 2014 Accepted: 26 May 2014

Published: 12 June 2014

\section{References}

1. Haffner SM, Lehto S, Ronnemaa T, Pyorala K, Laakso M: Mortality from coronary heart disease in subjects with type 2 diabetes and in nondiabetic subjects with and without prior myocardial infarction. N Engl J Med 1998, 339:229-234.

2. Di Filippo C, Marfella R, Cuzzocrea S, Piegari E, Petronella P, Giugliano D, Rossi F, D'Amico M: Hyperglycemia in streptozotocin-induced diabetic rat increases infarct size associated with low levels of myocardial HO-1 during ischemia/reperfusion. Diabetes 2005, 54:803-810.

3. Marfella R, D'Amico M, Di Filippo C, Piegari E, Nappo F, Esposito K, Berrino L, Rossi F, Giugliano D: Myocardial infarction in diabetic rats: role of hyperglycaemia on infarct size and early expression of hypoxia-inducible factor 1. Diabetologia 2002, 45:1172-1181.

4. Simpson PJ, Lucchesi BR: Free radicals and myocardial ischemia and reperfusion injury. J Lab Clin Med 1987, 110:13-30.

5. Verma S, Fedak PW, Weisel RD, Butany J, Rao V, Maitland A, Li RK, Dhillon B, Yau TM: Fundamentals of reperfusion injury for the clinical cardiologist. Circulation 2002, 105:2332-2336.

6. Toyoda T, Tsukamoto T, Takasu S, Shi L, Hirano N, Ban H, Kumagai T, Tatematsu M: Anti-inflammatory effects of caffeic acid phenethyl ester (CAPE), a nuclear factor-kappaB inhibitor, on Helicobacter pylori-induced gastritis in Mongolian gerbils. Int J Cancer 2009, 125:1786-1795.

7. Fesen MR, Pommier Y, Leteurtre F, Hiroguchi S, Yung J, Kohn KW: Inhibition of HIV-1 integrase by flavones, caffeic acid phenethyl ester (CAPE) and related compounds. Biochem Pharmacol 1994, 48:595-608.

8. Lee KW, Kang NJ, Kim JH, Lee KM, Lee DE, Hur HJ, Lee HJ: Caffeic acid phenethyl ester inhibits invasion and expression of matrix metalloproteinase in SK-Hep1 human hepatocellular carcinoma cells by targeting nuclear factor kappa B. Genes Nutr 2008, 2:319-322.

9. Velazquez C, Navarro M, Acosta A, Angulo A, Dominguez Z, Robles R, Robles-Zepeda R, Lugo E, Goycoolea FM, Velazquez EF, Astiazaran H, Hernandez J: Antibacterial and free-radical scavenging activities of Sonoran propolis. J App/ Microbiol 2007, 103:1747-1756.

10. Ozyurt H, Sogut S, Yildirim Z, Kart L, Iraz M, Armutcu F, Temel I, Ozen S, Uzun A, Akyol O: Inhibitory effect of caffeic acid phenethyl ester on bleomycine-induced lung fibrosis in rats. Clin Chim Acta 2004, 339:65-75.

11. Celik S, Erdogan S, Tuzcu M: Caffeic acid phenethyl ester (CAPE) exhibits significant potential as an antidiabetic and liver-protective agent in streptozotocin-induced diabetic rats. Pharmacol Res 2009, 60:270-276.

12. Celik S, Erdogan S: Caffeic acid phenethyl ester (CAPE) protects brain against oxidative stress and inflammation induced by diabetes in rats. Mol Cell Biochem 2008, 312:39-46.

13. Hishikawa K, Nakaki T, Fujita T: Oral flavonoid supplementation attenuates atherosclerosis development in apolipoprotein E-deficient mice. Arterioscler Thromb Vasc Biol 2005, 25:442-446.

14. Tsai SK, Lin MJ, Liao PH, Yang CY, Lin SM, Liu SM, Lin RH, Chih CL, Huang SS: Caffeic acid phenethyl ester ameliorates cerebral infarction in rats subjected to focal cerebral ischemia. Life Sci 2006, 78:2758-2762.

15. Ihan A, Koltuksuz U, Ozen S, Uz E, Ciralik H, Akyol O: The effects of caffeic acid phenethyl ester (CAPE) on spinal cord ischemia/reperfusion injury in rabbits. Eur J Cardiothorac Surg 1999, 16:458-463.

16. Gurel A, Armutcu F, Sahin S, Sogut S, Ozyurt H, Gulec M, Kutlu NO, Akyol O: Protective role of alpha-tocopherol and caffeic acid phenethyl ester on ischemia-reperfusion injury via nitric oxide and myeloperoxidase in rat kidneys. Clin Chim Acta 2004, 339:33-41.

17. Calikoglu M, Tamer L, Sucu N, Coskun B, Ercan B, Gul A, Calikoglu I, Kanik A: The effects of caffeic acid phenethyl ester on tissue damage in lung after hindlimb ischemia-reperfusion. Pharmacol Res 2003, 48:397-403.

18. Celik O, Turkoz Y, Hascalik S, Hascalik M, Cigremis Y, Mizrak B, Yologlu S: The protective effect of caffeic acid phenethyl ester on ischemia-reperfusion injury in rat ovary. Eur J Obstet Gynecol Reprod Biol 2004, 117:183-188.

19. Ozer MK, Parlakpinar $H$, Acet A: Reduction of ischemia-reperfusion induced myocardial infarct size in rats by caffeic acid phenethyl ester (CAPE). Clin Biochem 2004, 37:702-705.

20. Ozer MK, Parlakpinar H, Vardi N, Cigremis Y, Ucar M, Acet A: Myocardial ischemia/reperfusion-induced oxidative renal damage in rats: protection by caffeic acid phenethyl ester (CAPE). Shock 2005, 24:97-100.
21. Parlakpinar H, Sahna E, Acet A, Mizrak B, Polat A: Protective effect of caffeic acid phenethyl ester (CAPE) on myocardial ischemia-reperfusion-induced apoptotic cell death. Toxicology 2005, 209:1-14.

22. Huang SS, Liu SM, Lin SM, Liao PH, Lin RH, Chen YC, Chih CL, Tsai SK: Antiarrhythmic effect of caffeic acid phenethyl ester (CAPE) on myocardial ischemia/reperfusion injury in rats. Clin Biochem 2005, 38:943-947.

23. Tan J, Ma Z, Han L, Du R, Zhao L, Wei X, Hou D, Johnstone BH, Farlow MR Du Y: Caffeic acid phenethyl ester possesses potent cardioprotective effects in a rabbit model of acute myocardial ischemia-reperfusion injury. Am J Physiol Heart Circ Physiol 2005, 289:H2265-H2271.

24. Yang J, Kerwin SM, Bowman PD, Stavchansky S: Stability of caffeic acid phenethyl amide (CAPA) in rat plasma. Biomed Chromatogr 2012, 26:594-598.

25. Yang J, Bowman PD, Kerwin SM, Stavchansky S: Development and validation of an LCMS method to determine the pharmacokinetic profiles of caffeic acid phenethyl amide and caffeic acid phenethyl ester in male Sprague-Dawley rats. Biomed Chromatogr 2014, 28:241-246.

26. Son S, Lewis BA: Free radical scavenging and antioxidative activity of caffeic acid amide and ester analogues: structure-activity relationship. J Agric Food Chem 2002, 50:468-472.

27. Boudreau LH, Maillet J, LeBlanc LM, Jean-Francois J, Touaibia M, Flamand N, Surette ME: Caffeic acid phenethyl ester and its amide analogue are potent inhibitors of leukotriene biosynthesis in human polymorphonuclear leukocytes. PLoS One 2012, 7:e31833.

28. Yang J, Marriner GA, Wang X, Bowman PD, Kerwin SM, Stavchansky S: Synthesis of a series of caffeic acid phenethyl amide (CAPA) fluorinated derivatives: comparison of cytoprotective effects to caffeic acid phenethyl ester (CAPE). Bioorg Med Chem 2010, 18:5032-5038.

29. Nishioka T, Watanabe J, Kawabata J, Niki R: Isolation and activity of $\mathrm{N}$ - -coumaroyltyramine, an a-glucosidase Inhibitor in Welsh onion (Allium fistulosum). Biosci Biotechnol Biochem 1997, 61:4.

30. Yamazaki $Y$, Kawano $Y$, Uebayasi M: Induction of adiponectin by natural and synthetic phenolamides in mouse and human preadipocytes and its enhancement by docosahexaenoic acid. Life Sci 2008, 82:290-300.

31. Ho YJ, Chen WP, Chi TC, Chang Chien CC, Lee AS, Chiu HL, Kuo YH, Su MJ: Caffeic acid phenethyl amide improves glucose homeostasis and attenuates the progression of vascular dysfunction in Streptozotocin-induced diabetic rats. Cardiovasc Diabetol 2013, 12:99.

32. Weng YC, Chiu HL, Lin YC, Chi TC, Kuo YH, Su MJ: Antihyperglycemic effect of a caffeamide derivative, KS370G, in normal and diabetic mice. J Agric Food Chem 2010, 58:10033-10038.

33. Weng YC, Chuang ST, Lin YC, Chuang CF, Chi TC, Chiu HL, Kuo YH, Su MJ: Caffeic acid phenylethyl amide protects against the metabolic consequences in diabetes mellitus induced by diet and streptozocin. Evid Based Complement Alternat Med 2012, 2012:984780.

34. Weng YC, Chuang CF, Chuang ST, Chiu HL, Kuo YH, Su MJ: KS370G, a synthetic caffeamide derivative, improves left ventricular hypertrophy and function in pressure-overload mice heart. Eur J Pharmacol 2012, 684:108-115.

35. Ku PM, Chen L, Liang JR, Cheng KC, Li YX, Cheng JT: Molecular role of GATA binding protein 4 (GATA-4) in hyperglycemia-induced reduction of cardiac contractility. Cardiovasc Diabetol 2011, 10:57

36. Chi TC, Ho YJ, Chen WP, Chi TL, Lee SS, Cheng JT, Su MJ: Serotonin enhances beta-endorphin secretion to lower plasma glucose in streptozotocin-induced diabetic rats. Life Sci 2007, 80:1832-1838.

37. Katovich MJ, Meldrum MJ, Vasselli JR: Beneficial effects of dietary acarbose in the streptozotocin-induced diabetic rat. Metabolism 1991, 40:1275-1282.

38. Chang WL, Lee SS, Su MJ: Attenuation of post-ischemia reperfusion injury by thaliporphine and morphine in rat hearts. J Biomed Sci 2005, 12:611-619.

39. Chiao CW, Lee SS, Wu CC, Su MJ: N-Allylsecoboldine as a novel agent prevents acute renal failure during endotoxemia. Eur J Pharmacol 2006, 535:291-300.

40. Barone FC, Hillegass LM, Price WJ, White RF, Lee EV, Feuerstein GZ, Sarau HM, Clark RK, Griswold DE: Polymorphonuclear leukocyte infiltration into cerebral focal ischemic tissue: myeloperoxidase activity assay and histologic verification. J Neurosci Res 1991, 29:336-345.

41. Janero DR: Malondialdehyde and thiobarbituric acid-reactivity as diagnostic indices of lipid peroxidation and peroxidative tissue injury. Free Radic Biol Med 1990, 9:515-540 
42. Chen WP, Tzeng HJ, Ku HC, Ho YJ, Lee SS, Su MJ: Thaliporphine ameliorates cardiac depression in endotoxemic rats through attenuating TLR4 signaling in the downstream of TAK-1 phosphorylation and NF-kappaB signaling. Naunyn Schmiedebergs Arch Pharmacol 2010, 382:441-453.

43. Van Dantzig JM, Delemarre BJ, Bot H, Visser CA: Left ventricular thrombus in acute myocardial infarction. Eur Heart J 1996, 17:1640-1645.

44. Sun H, Mohri M, Shimokawa H, Usui M, Urakami L, Takeshita A: Coronary microvascular spasm causes myocardial ischemia in patients with vasospastic angina. J Am Coll Cardiol 2002, 39:847-851.

45. Bourassa MG: Silent myocardial ischemia after coronary angioplasty: distinguishing the shadow from the substance. J Am Coll Cardiol 1992, 19:1410-1411.

46. Suleiman MS, Zacharowski K, Angelini GD: Inflammatory response and cardioprotection during open-heart surgery: the importance of anaesthetics. Br J Pharmacol 2008, 153:21-33.

47. McCord JM: Free radicals and myocardial ischemia: overview and outlook. Free Radic Biol Med 1988, 4:9-14.

48. Hsu LY, Lin CF, Hsu WC, Hsu WL, Chang TC: Evaluation of polyphenolic acid esters as potential antioxidants. Biol Pharm Bull 2005, 28:1211-1215

49. Jones SP, Girod WG, Palazzo AJ, Granger DN, Grisham MB, Jourd'Heuil D, Huang PL, Lefer DJ: Myocardial ischemia-reperfusion injury is exacerbated in absence of endothelial cell nitric oxide synthase. Am J Physiol 1999, 276:H1567-H1573

50. Alp NJ, Channon KM: Regulation of endothelial nitric oxide synthase by tetrahydrobiopterin in vascular disease. Arterioscler Thromb Vasc Biol 2004, 24:413-420.

51. Randriamboavonjy V, Fleming I: Endothelial nitric oxide synthase (eNOS) in platelets: how is it regulated and what is it doing there? Pharmacol Rep 2005, 57(Suppl):59-65.

52. Forstermann $U$, Munzel T: Endothelial nitric oxide synthase in vascular disease: from marvel to menace. Circulation 2006, 113:1708-1714.

53. Lu DY, Huang BR, Yeh WL, Lin HY, Huang SS, Liu YS, Kuo YH: Antineuroinflammatory effect of a novel caffeamide derivative, KS370G, in microglial cells. Mol Neurobiol 2013, 48:863-874.

54. Hicks KK, Seifen E, Stimers JR, Kennedy RH: Effects of streptozotocininduced diabetes on heart rate, blood pressure and cardiac autonomic nervous control. J Auton Nerv Syst 1998, 69:21-30.

55. Huang JP, Huang SS, Deng JY, Chang CC, Day YJ, Hung LM: Insulin and resveratrol act synergistically, preventing cardiac dysfunction in diabetes, but the advantage of resveratrol in diabetics with acute heart attack is antagonized by insulin. Free Radic Biol Med 2010, 49:1710-1721.

56. Westermann D, Rutschow S, Jager S, Linderer A, Anker S, Riad A, Unger T, Schultheiss HP, Pauschinger M, Tschope C: Contributions of inflammation and cardiac matrix metalloproteinase activity to cardiac failure in diabetic cardiomyopathy: the role of angiotensin type 1 receptor antagonism. Diabetes 2007, 56:641-646.

57. Litwin SE, Raya TE, Anderson PG, Daugherty S, Goldman S: Abnormal cardiac function in the streptozotocin-diabetic rat. Changes in active and passive properties of the left ventricle. J Clin Invest 1990, 86:481-488.

58. Boudina S, Abel ED: Diabetic cardiomyopathy revisited. Circulation 2007, 115:3213-3223.

59. Galiñanes M, Fowler AG: Role of clinical pathologies in myocardial injury following ischaemia and reperfusion. Cardiovasc Res 2004, 61:512-521.

60. Yong QC, Thomas CM, Seqqat R, Chandel N, Baker KM, Kumar R: Angiotensin type 1a receptor-deficient mice develop diabetes-induced cardiac dysfunction, which is prevented by renin-angiotensin system inhibitors. Cardiovasc Diabetol 2013, 12:169.

61. Gibson CL, Srivastava K, Sprigg N, Bath PM, Bayraktutan U: Inhibition of Rho-kinase protects cerebral barrier from ischaemia-evoked injury through modulations of endothelial cell oxidative stress and tight junctions. J Neurochem 2014, 129:816-826.

62. Guo R, Liu BX, Zhou SP, Zhang BC, Xu YW: The protective effect of fasudi on the structure and function of cardiac mitochondria from rats with type 2 diabetes induced by streptozotocin with a high-fat diet is mediated by the attenuation of oxidative stress. Biomed Res Int 2013 2013:430791.

63. Pearson JT, Jenkins MJ, Edgley AJ, Sonobe T, Joshi M, Waddingham MT, Fujii $Y$, Schwenke DO, Tsuchimochi H, Yoshimoto M, Umetani K, Kelly DJ, Shirai M: Acute Rho-kinase inhibition improves coronary dysfunction in vivo, in the early diabetic microcirculation. Cardiovasc Diabetol 2013, 12:111.
64. Guan SJ, Ma ZH, Wu YL, Zhang JP, Liang F, Weiss JW, Guo QY, Wang JY, Ji ES, Chu L: Long-term administration of fasudil improves cardiomyopathy in streptozotocin-induced diabetic rats. Food Chem Toxicol 2012 50:1874-1882.

65. Funakoshi Y, Ichiki T, Shimokawa H, Egashira K, Takeda K, Kaibuchi K, Takeya M, Yoshimura T, Takeshita A: Rho-kinase mediates angiotensin II-induced monocyte chemoattractant protein-1 expression in rat vascular smooth muscle cells. Hypertension 2001, 38:100-104.

66. Fang ZY, Prins JB, Marwick TH: Diabetic cardiomyopathy: evidence, mechanisms, and therapeutic implications. Endocr Rev 2004, 25:543-567.

67. Soliman H, Craig GP, Nagareddy P, Yuen VG, Lin G, Kumar U, McNeill JH, Macleod KM: Role of inducible nitric oxide synthase in induction of RhoA expression in hearts from diabetic rats. Cardiovasc Res 2008, 79:322-330.

68. Wu RP, Hayashi T, Cottam HB, Jin G, Yao S, Wu CC, Rosenbach MD, Corr M, Schwab RB, Carson DA: Nrf2 responses and the therapeutic selectivity of electrophilic compounds in chronic lymphocytic leukemia. Proc Natl Acad Sci U S A 2010, 107:7479-7484.

69. Surh YJ: Cancer chemoprevention with dietary phytochemicals. Nat Rev Cancer 2003, 3:768-780.

70. Lee Y, Shin DH, Kim JH, Hong S, Choi D, Kim YJ, Kwak MK, Jung Y: Caffeic acid phenethyl ester-mediated Nrf2 activation and I kappa B kinase inhibition are involved in NF kappa B inhibitory effect: Structural analysis for NF kappa B inhibition. Eur J Pharmacol 2010, 643:21-28.

71. Yang J, Wang $X$, Stavchansky S, Bynum J, Bowman P: Structure activity relationships of caffeic acid phenethyl ester (CAPE) and its amide derivative caffeic acid phenethyl amide (CAPA) against oxidant stress in human endothelial cells. FASEB J 2009, 23(Meeting Abstract Suppl):937-938.

doi:10.1186/1475-2840-13-98

Cite this article as: Ho et al:: Caffeic acid phenethyl amide ameliorates ischemia/reperfusion injury and cardiac dysfunction in streptozotocin-induced diabetic rats. Cardiovascular Diabetology 2014 13:98.

\section{Submit your next manuscript to BioMed Central and take full advantage of:}

- Convenient online submission

- Thorough peer review

- No space constraints or color figure charges

- Immediate publication on acceptance

- Inclusion in PubMed, CAS, Scopus and Google Scholar

- Research which is freely available for redistribution 